\section{Unreproducible results}

SIR-Amid the palaver generated in both the scientific and the popular press by investigations into the unreproducible results reported by Weaver et al. (Cell $\mathbf{4 5}$, $247 ; 1986)$, and more recently by Davenas et al. (Nature 333, 816; 1988), nobody seems to have noticed how odd the tone of both investigations has been. The most logical explanation for the irreproducibility of both the Weaver et al. and Benveniste group results is simple human error: sloppy experimental procedure, or perhaps unforeseen artefacts that were not adequately controlled for, to be more charitable. Nobody who has done experimental science in a serious way would be surprised at that: it can be very difficult to design experiments so that all sources of systematic error are accounted for, and scientists, being human, make mistakes. Added to this fact is the common tendency of research workers to have a vested interest in a particular theory, which can cause them to overinterpret data or to be careless about considering alternative explanations, especially those that involve artefact. Yet the tone of the investigation into both papers has been that of a grand jury looking for evidence of a crime. The elaborate security precautions taken by the Nature team on the expedition to the Benveniste laboratory are inconsistent with a simple inquiry into human error. Rather, they are the precautions of people who expect to encounter deliberate falsification.

Scepticism is healthy in science, but cynicism can have unfortunate consequences. One of them is the extreme defensiveness that it creates in its targets. In his reply to the Nature investigation, Benveniste adopts a tone of the falsely accused that culminates in an anguished diatribe against "Salem witch hunts or McCarthy-like prosecution". This is not a reasonable response for a person who has only been shown to be in error (and that may be more revealing about its author than he realizes) but it is consistent with the tone of the times. And it seems to me that we are all served poorly by such an atmosphere. It polarizes discussions, creates an emotional rather than an intellectual climate for investigation, and leaves the public with a sense that science is a monolithic institution, hostile to new ideas and venomous in its defence of established ones.

What is the cause of this climate? I think it is the perception on the part of the researchers that to make an error is the worst thing that can happen to a scientist. Science is now a huge activity, with large numbers of laboratories competing intensely in almost every field. Frequently, the only way one's own discoveries can be distinguished from those of one's competitors is by exaggerating the mistakes or wrong interpretations of the opponents.

When error can result in permanent harm to one's career, and when every mistake is seized upon as evidence of incompetence, a defensive attitude is inevitable. Excessive defensiveness leads to compounding of the error, for the researcher is then unwilling to believe evidence that a mistake was made. So pervasive has this process become that it is now considered harmful to one's reputation and career to publish what turns out to be a wrong interpretation of data even if the data are accurate and admit of more than one interpretation. The result, of course, is that people cling to incorrect interpretations longer than they should, which sets back the entire scientific process.

Fraud is a very serious matter, but I think it is more apt to occur in a climate where mistakes are treated too harshly. How many instances of deception actually begin as attempts to cover up honest mistakes I do not know, but surely when the consequences of making an honest mistake are nearly as severe as the consequence of fraud, and when the machinery used to investigate error comes to resemble that used to deal with suspected fraud, more people will consider the use of falsification to avoid the stigma of having

SIR-I submit that it would be easier to prove an incredible result like Benveniste's to scientists than it would be to disprove it to homoeopaths. Scientists accept the verdict of reproducibility. It is, of course, impossible to duplicate exactly any experiment. One must discount the effect of a myriad of minor variables. Homoeopaths, as evidenced by the comments of David Reilly (New Scientist 4 August 1988, p.30) are not willing to do this. If Benveniste's experiment turns out to be irreproducible, he says, diurnal rhythms or some electrical pollution in the laboratory may be the cause. Within the context of homoeopathy, this might make sense. Who is to say that leaving a television on next to the laboratory is unimportant, or that the experiment must be done at night, or not within $100 \mathrm{~km}$ of a nuclear power plant and so on? PETER J. Lipowicz 716 Turner $N E$,

Albuquerque, New Mexico 87123 USA

SIR-In my teaching, I encourage students to review freshman chemistry. Many resist and some insist that as biologists they do not need to know chemistry. If they intend to pursue imitative research, such indifference may be defensible. On the other hand, original research requires a general science background suf- erred. Thus, the present climate may actually increase the likelihood of the offence it is trying to stamp out.

What is needed is a decriminalization of error. Science often advances on the strength of theories that turn out to be incorrect, for a wrong hypothesis can produce many excellent experiments. (Columbus, after all, acting on a false hypothesis, bumped into a new world.) Appointments committees should look at the total record of a scientist, and not overemphasize a single mistake, especially if the mistake was corrected by the person who made it. University professors who train graduate students and postdocs must adopt this attitude and teach it to their students, so that the next generation of scientists will start from a different ethos.

I do not believe the decriminalization of error will lead to more error. Mistakes happen because careful research is hard and fallible human beings try to do it. But a climate in which self-correction is encouraged makes detection and admission of error easier. And it is the detection of error, and its correction, that is the real problem. All that is needed is the recognition, commonplace in other forms of human endeavour, that mistakes are the path to growth, especially when one discovers one's own, and learns from them.

Gregory A. Petsko

Department of Chemistry,

Massachusetts Institute of Technology, Cambridge, Massachusetts 02139, USA

ficient to recognize nonsense. The 'controversial' basophil neutralization paper nicely illustrates the distress that can ensue when a biologist knows less of atomic theory and water structure than a competent freshman chemist. Whatever embarrassment accrues to the authors of this paper should serve as a warning to those who promote lofty principles from narrow understanding. Perhaps narrow technical interests should be rewarded with special degrees such as Master of Mediocrity or Doctor of Imitation (D.Im.). Leslie C. Lane

Department of Plant Pathology,

University of Nebraska,

Lincoln, Nebraska 68583-0722, USA

SIR-As Randi so rightly says, reports of unicorns need to be checked with particular care. Readers of Nature, and past and prospective authors, deserve an explanation of how it was that Nature did not make the elementary check to see that Benveniste's degranulation counts were consistent with the expected poissonian distribution, either when he first submitted the paper, or before the extended paper was accepted for publication.

Building Research Station,

B.H. BLAND

Garston, Watford WD2 7JR, UK 